\title{
Malperfusion rather than merely timing of operative repair determines early and late outcome in type $\mathbf{A}$ aortic dissection
}

\author{
Pradeep Narayan, FRCS[CTh], Chris A. Rogers, PhD, Umberto Benedetto, MD, Massimo Caputo, MD, \\ Gianni D. Angelini, FRCS, and Alan J. Bryan, FRCS[CTh]
}

\begin{abstract}
Background: Although generally better outcomes are reported in patients undergoing early repair of type A aortic dissection, patients who survive the first 48 hours self-select themselves toward better outcomes as well. Malperfusion is another important determinant of outcome in these patients. The aim of this study was to examine the hypothesis that malperfusion, not the timing of operation, is the dominant determinant of outcome in repair of type A aortic dissection.
\end{abstract}

Methods: A total of 205 patients underwent operative repair of acute type A aortic dissection in our hospital over a 17 -year period. The time from symptom onset to surgical repair was reliably established in 152 cases. Patients were grouped into those who had undergone surgery within 12 hours of symptom onset (early surgery group; $n=72[47 \%]$ ) and those who underwent surgery beyond 12 hours of symptom onset (late surgery group; $n=80$ [53\%]).

Results: Thirty-day mortality was similar in the 2 groups (early surgery: $19.4 \%$ [95\% confidence interval [CI] 12.0\%-30.6\%]; late surgery: $13.8 \%$ [95\% CI, $7.9 \%-23.5 \%$ ] $P=.08$ ). The log-rank test for equality of survivor functions was 0.08 . However, malperfusion with hemodynamic compromise was more common in the early surgery group $(47 \%$ vs $31 \% ; P=.029)$ and was identified as an independent predictor of long-term mortality (hazard ratio, 2.65; 95\% CI, $1.21-5.79 ; P=.014)$.

Conclusions: Malperfusion at presentation rather than timing of intervention is the major risk factor of death both in the hospital and at long-term follow-up in patients undergoing surgery for type A aortic dissection. (J Thorac Cardiovasc Surg 2017;154:81-6)

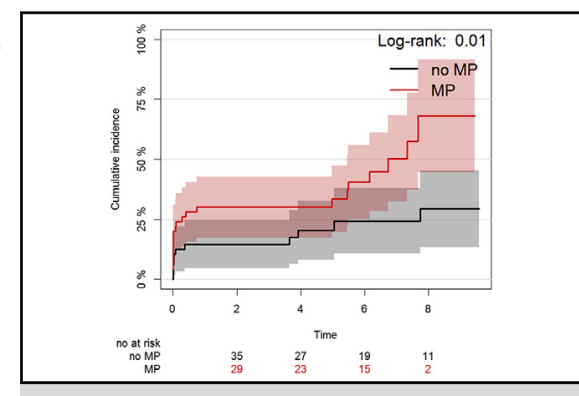

Survival comparison of patients with and without malperfusion.

\section{Central Message}

The presence or absence of malperfusion is the main determinant of outcomes in patients undergoing repair of aortic dissection. Early repair is advocated to prevent the development of organ malperfusion.

\section{Perspective}

In patients with aortic dissection, those who undergo early surgical repair and those surviving for the first 48 hours tend to have better outcomes, owing to the absence of malperfusion Malperfusion developing despite early presentation represents more severe pathology and is associated with poorer outcomes. Although early repair remains the standard of care, outcomes are determined more by the presence of malperfusion than by the timing of surgery.

See Editorial Commentary page 87.
Acute type A aortic dissection can be difficult to diagnose owing to the varied clinical presentations. Sudden severe chest pain, the most common presenting symptom, often directs investigations inappropriately toward acute coronary syndrome (ACS), but may be absent in up to $20 \%$ of cases.

\footnotetext{
From the Bristol Heart Institute, University of Bristol, Bristol, United Kingdom. This research was supported by the National Institute for Health Research's Bristol Cardiovascular Biomedical Research Unit and the British Heart Foundation.

Received for publication July 6, 2016; revisions received Feb 23, 2017; accepted for publication March 8, 2017; available ahead of print April 15, 2017.

Address for reprints: Alan J. Bryan, FRCS[CTh], Bristol Heart Institute, University Hospitals Bristol NHS Foundation Trust, Bristol Royal Infirmary, Bristol BS2 8HW, United Kingdom (E-mail: Alan.Bryan@uhbristol.nhs.uk). $0022-5223 / \$ 36.00$

Crown Copyright (C) 2017 Published by Elsevier Inc. on behalf of The American Association for Thoracic Surgery

http://dx.doi.org/10.1016/j.jtcvs.2017.03.041
}

Other signs and symptoms usually associated with aortic dissection and routine investigations are neither sensitive nor specific for the condition. ${ }^{2}$ Misdiagnosis leads to delays in surgical repair in up to $68 \%$ of cases. ${ }^{3}$ Therefore, it has been suggested that rapid diagnosis of aortic dissection mandates a high degree of clinical suspicion, and clinical algorithms have been developed to offer the best chance of diagnosis. $^{4,5}$

Scanning this QR code will take you to a supplemental video for the article.

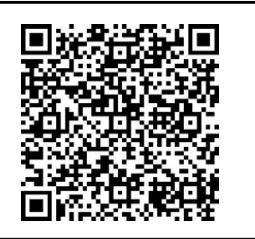




\section{Abbreviations and Acronyms \\ ACS = acute coronary syndrome \\ $\mathrm{CI}=$ confidence interval \\ $\mathrm{CPR}=$ cardiopulmonary resuscitation \\ GI $=$ gastrointestinal \\ $\mathrm{IQR}=$ interquartile range \\ NSTS $=$ National Health Service Strategic Tracing Service}

The delay in surgical repair of acute type A aortic dissection has been considered to be directly related to poor outcomes. In the absence of surgical correction, mortality increases by $1 \%$ to $2 \%$ per hour after onset of symptoms and has been reported to exceed $35 \%$ in the first 24 hours. ${ }^{6}$ Early diagnosis allows for surgical repair before the development of cardiac tamponade or other consequences of malperfusion, and provides the patient with the best chance of survival. ${ }^{7}$ The importance of malperfusion as a determinant of outcome also has been stressed by the International Registry of Acute Aortic Dissection, which has identified increased rates of myocardial or mesenteric ischemia, kidney failure, hypotension, cardiac tamponade, and limb ischemia in nonsurvivors following aortic dissection. ${ }^{8}$

Although there is a sound scientific explanation for the better outcomes in patients who undergo early surgery, ${ }^{9}$ it also is generally accepted that patients who survive the first 48 hours self-select themselves toward better outcomes following surgical repair, perhaps owing to the absence of malperfusion. ${ }^{3}$ Essentially, these patients have pathophysiologically avoided the development of malperfusion secondary to aortic dissection. The most obvious extension of this effect is the better natural history of intramural hematoma, given that it is not associated with malperfusion.

Therefore, it might be argued that outcomes are related less to the timing of surgical repair than to the presence or absence of malperfusion. Timing merely acts as a surrogate marker, with immediate surgery preventing the development of malperfusion and delayed surgery selecting patients with minimal or no malperfusion. Consequently, in the present study, we examined the hypothesis that it is the development of malperfusion, not the timing of surgery, that has a direct correlation with outcomes following surgical repair of type A aortic dissection.

\section{METHODS \\ Patient Selection}

All patients undergoing surgical treatment for type A aortic dissection at the Bristol Heart Institute over a 17-year period were included in this study. The interval between symptom onset and surgical intervention was established through careful case note review. The intervals between symptom onset and surgical repair and between presentation to our institution and intervention were calculated. The median time between symptom onset and initiation of surgical repair was 12.5 hours (interquartile range
[IQR], 9-24.25 hours); therefore, we used a cutoff of 12 hours to divide the study participants into 2 groups of comparable size: patients who underwent surgery within 12 hours of symptom onset (early surgery group) and those who did so beyond 12 hours after symptom onset (late surgery group).

Malperfusion was defined as the presence of limb ischemia (including absent pulses), cerebrovascular event (syncope, transient ischemic attack, or stroke), objective evidence of visceral malperfusion, anuria or persistent oliguria, evidence of myocardial ischemia, and presence of significant hemodynamic compromise or shock secondary to cardiac tamponade or severe aortic regurgitation. Even in the presence of malperfusion, our strategy was to treat the aortic dissection first and deal with any residual end-organ malperfusion later, as necessary, during the same theatre session.

\section{Data Collection and Definitions}

Demographic, preoperative, perioperative, and postoperative data were collected prospectively for all patients undergoing cardiac surgery and then entered into a database (Patient Analysis and Tracking System; Dendrite Clinical Systems, London, United Kingdom). The regression model included 2 variables, the timing of surgery ( $\leq 12$ hours vs $>12$ hours) and the presence or absence of malperfusion. All types of malperfusion were considered together. Shock and rupture were considered cardiac malperfusion. Deaths after hospital discharge were identified from mortality data provided by the National Health Service Strategic Tracing Service (NSTS). All patients were successfully matched to the NSTS database. Definitions of operative priority, premorbid conditions, and postoperative complications were those defined by the National Adult Cardiac Surgical Database and accepted by the Society for Cardiothoracic Surgery of Great Britain and Ireland (available at www.scts.org).

\section{Operative Techniques}

For dissections extending beyond the ascending aorta, an open distal anastomosis was routinely used. Spiral tears extending along the undersurface of the arch were treated with a beveled distal anastomosis (hemiarch replacement). In cases of tears within the aortic arch, complete aortic arch replacement was performed. Only those operations involving 2 or more distal anastomoses to the distal aorta and 1 or more aortic arch branches were considered aortic arch operations.

Anesthetic and surgical techniques, along with strategies for cerebral protection and blood conservation, have been described previously. ${ }^{10}$ For cases of malperfusion presenting with aortic dissection, we adopted the policy of repairing the aortic dissection first. Any residual end-organ malperfusion was treated later, often during the same theatre session.

\section{Statistical Analysis}

Baseline and operative characteristics were compared using the $\chi^{2}$ test or Fisher's exact test for categorical variables and Wilcoxon's rank-sum test for continuous variables. Crude mortality rates were estimated using the Kaplan-Meier method and compared using the log-rank test. The effects of malperfusion and time from symptom onset to surgery on survival were adjusted for other covariates using Cox regression. Covariates included in the model were age, sex, left ventricular ejection fraction, presence of Marfan's disease, reoperation, aortic root replacement, arch replacement, and concomitant coronary artery bypass grafting. Time to surgery was forced as linear and nonlinear terms (3-knot spline), and models were compared by analysis of variance to investigate nonlinearity between the time of symptom onset and survival. A possible interaction between malperfusion and time to surgery on survival was tested as well. All analyses were performed using Stata version 9.2 (StataCorp, College Station, Tex).

\section{RESULTS}

A total of 205 procedures were performed during the study period. The time from hospital admission to 
TABLE 1. Types of malperfusion seen in patients undergoing surgery early and late for type A aortic dissection

\begin{tabular}{lcc}
\hline \multicolumn{1}{c}{ Type of malperfusion } & $\begin{array}{c}\text { Early surgery } \\
(\mathbf{n}=\mathbf{7 2})\end{array}$ & $\begin{array}{c}\text { Late surgery } \\
(\mathbf{n}=\mathbf{8 0})\end{array}$ \\
\hline Cardiogenic shock necessitating & 2 & 0 \\
$\quad$ preoperative CPR, $\mathrm{n}$ & & \\
Cardiac tamponade, $\mathrm{n}$ & 7 & 4 \\
Severe aortic regurgitation, $\mathrm{n}$ & 8 & 3 \\
Renal malperfusion, $\mathrm{n}$ & 6 & 9 \\
Limb ischemia, n & 11 & 12 \\
Cerebral malperfusion, n & 5 & 11 \\
GI malperfusion, n & 0 & 2 \\
\hline
\end{tabular}

CPR, Cardiopulmonary resuscitation; $G I$, gastrointestinal.

intervention was ascertained in all cases; however, the time from symptom onset to surgical repair could be determined reliably in only 152 patients $(74 \%)$. The median time between symptom onset and operation was 12.5 hours (IQR, 9-24.25 hours). Seventy-two patients ( $47 \%$ ) underwent surgery within 12 hours of symptom onset, and 80 patients $(53 \%)$ underwent surgery beyond 12 hours of symptom onset. The median time between arrival at our center and surgical repair was 3 hours (IQR, 1.5-7 hours). Malperfusion was present in 60 of the 152 patients (39\%). Evidence of organ malperfusion was more common in the patients undergoing early surgical repair, but the difference between the 2 groups was not statistically significant $(48.6 \%$ $[\mathrm{n}=35]$ vs $31.3 \%[\mathrm{n}=25] ; P=.29)$. The various organ malperfusions seen in the 2 groups are listed in Table 1 . All other baseline characteristics were similar in the 2 groups (Table 2). Apart from a significantly higher proportion of patients requiring aortic valve replacement or repair/ resuspension in the early group, the surgical procedures were essentially similar in the 2 groups (Table 2). In terms of postoperative morbidity, there was no significant difference in outcomes between the 2 groups (Table 3 ).

Early mortality was also similar in the 2 groups. There were 14 deaths within 30 days in the early surgery group (19.4\%; 95\% CI 12.0-30.6), compared with 11 deaths in the late surgery group $(13.8 \% ; 95 \%$ CI, 7.9-23.5) $(P=.08)$. There was no difference in late survival between patients undergoing early ( $<12$ hours) and late ( $>12$ hours) operations (Figure 1). Multivariate analysis results for late mortality are reported in Table 4. Malperfusion (HR, 2.65; 95\% CI, 1.21-5.79; $P=.01$ ) (Figure 2) and concomitant coronary artery bypass grafting (HR, 3.03; 95\% CI, 1.12$8.19 ; P=.03)$ were identified as independent predictors of survival (Table 4). Time to surgery (nonlinear) showed an inverse relationship with late mortality (univariate $P=.03$ ), with a first phase showing a decrease in mortality during the first 24 hours, followed by a second steady phase (Figure 3). However, when time to surgery was adjusted for other covariates, including malperfusion, it did not significantly affect survival $(P=.09)$. No significant interaction was found between malperfusion and time to surgery affecting survival $(P=.34)$.

\section{DISCUSSION}

The main finding of the present study is that almost $40 \%$ of patients undergoing repair of type A aortic dissection had evidence of malperfusion. The second important finding is that the presence of malperfusion was associated with significantly increased risk of death in both the short-term and long-term follow-up. Regarding timing, delayed operation was associated with a reduced risk, but this reduction was not significant when malperfusion was accounted for.

Interesting information related to time-dependent outcomes has emerged from various studies and registries.

TABLE 2. Baseline and operative characteristics of the study population

\begin{tabular}{|c|c|c|c|}
\hline Characteristic & Early surgery $(n=72)$ & Late surgery $(\mathbf{n}=\mathbf{8 0})$ & $P$ value \\
\hline Age, y, median (IQR) & $62(54-69)$ & $63(49-70)$ & .42 \\
\hline Male sex, $\mathrm{n}(\%)$ & $56(77.8)$ & $55(68.8)$ & .21 \\
\hline Hypertension, $\mathrm{n}(\%)$ & $41(57.8)$ & $38(48.7)$ & .27 \\
\hline Redo surgery, n (\%) & $4(6.5)$ & $7(9.7)$ & .49 \\
\hline Peripheral vascular disease, $\mathrm{n}(\%)$ & $6(8.3)$ & $4(5.1)$ & .43 \\
\hline EuroSCORE, median (IQR) & $9(7-12)$ & $9(6-12)$ & .96 \\
\hline Malperfusion, $\mathrm{n}(\%)$ & $35(48.6)$ & $25(31.3)$ & .029 \\
\hline Marfan syndrome, $\mathrm{n}(\%)$ & $1(1.38)$ & $7(8.75)$ & .06 \\
\hline Concomitant coronary artery disease, $\mathrm{n}(\%)$ & $4(5.55)$ & $8(10)$ & .37 \\
\hline $\mathrm{CPB}$ time, min, median (IQR) & $166(132-195)$ & $152(125-189)$ & .36 \\
\hline Cross-clamp time, min, median (IQR) & $73(57-101)$ & $76(61-108)$ & .60 \\
\hline Circulatory arrest time, min, median (IQR) & $36(27-51)$ & $37(28-62)$ & .78 \\
\hline Concomitant CABG, n (\%) & $9(12.5)$ & $10(12.5)$ & $>.99$ \\
\hline Concomitant MVR, n (\%) & $1(1.4)$ & $2(2.6)$ & $>.99$ \\
\hline Arch replacement, n (\%) & $5(6.9)$ & $8(10.4)$ & .46 \\
\hline Valve replacement, $\mathrm{n}(\%)$ & $17(23.6)$ & $21(26.9)$ & .015 \\
\hline Repair/resuspension, n (\%) & $15(20.8)$ & $4(5.1)$ & \\
\hline
\end{tabular}

$I Q R$, Interquartile range; $C P B$, cardiopulmonary bypass; $C A B G$, coronary artery bypass grafting; $M V R$, mitral valve replacement. 
TABLE 3. Postoperative outcomes

\begin{tabular}{lccc}
\hline \multicolumn{1}{c}{ Characteristic } & $\begin{array}{c}\text { Early surgery } \\
(\mathbf{n = 7 2})\end{array}$ & $\begin{array}{c}\text { Late surgery } \\
(\mathbf{n = 8 0 )}\end{array}$ & $\boldsymbol{P}$ value \\
\hline Neurologic complication, n (\%) & $10(15.6)$ & $10(13.3)$ & .70 \\
Renal failure, n (\%) & $8(11.1)$ & $11(13.8)$ & .62 \\
Reoperation for bleeding, n (\%) & $8(11.4)$ & $9(11.4)$ & $>.99$ \\
Tracheostomy, n (\%) & $10(15.4)$ & $19(26.4)$ & .12 \\
Septicemia, n (\%) & $6(9.8)$ & $9(14.8)$ & .41 \\
Intensive care unit stay, d, & $4(2-6)$ & $5(3-12)$ & .06 \\
$\quad$ median (IQR) & & & \\
Hospital stay, d, median (IQR) & $13(10-19)$ & $14(10-22)$ & .45 \\
\hline
\end{tabular}

$I Q R$, Interquartile range.

Analysis of the International Registry of Acute Aortic Dissection data reveals an incremental risk of death of $1 \%$ to $2 \%$ for every hour without repair. ${ }^{6}$ After 24 hours, there is a slightly lower risk of death, ${ }^{11}$ which continues to decrease between days 5 and 30 at a rate of $1 \%$ per day. ${ }^{12}$ Nonetheless, acute type A aortic dissection remains a true surgical emergency, and the consensus opinion is to perform surgical repair as soon as possible, especially within the first 48 hours and in the presence of malperfusion. ${ }^{6}$ The variability in outcomes apparently influenced by time can be explained by the onset and progression of malperfusion, and thus time-related outcomes are essentially a function of time-related changes in organ perfusion. It has been proposed that malperfusion is a dynamic process and that patients can present in different stages of organ perfusion: no malperfusion; subclinical malperfusion, defined as organ malperfusion with preserved function; and malperfusion syndrome with overt clinical organ dysfunction. ${ }^{13,14}$ Thus, timing merely represents patients at different points on this malperfusion scale. Apart from

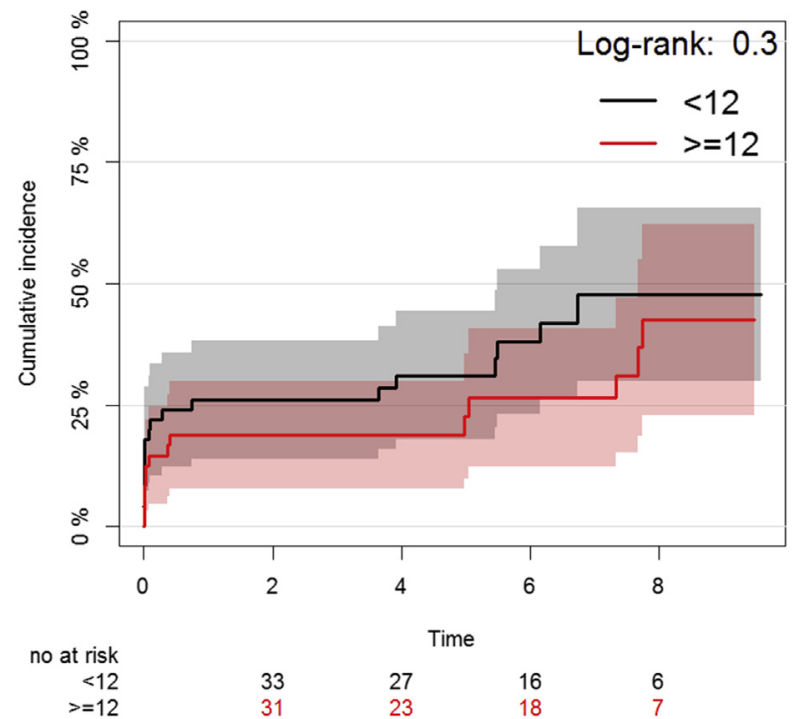

FIGURE 1. Survival comparison of patients undergoing early ( $<12$ hours) and late ( $>12$ hours) operations.
TABLE 4. Multivariate analysis of different variables on outcome

\begin{tabular}{lccc}
\hline \multicolumn{1}{c}{ Outcome } & HR & $\mathbf{9 5} \%$ CI & $\boldsymbol{P}$ value \\
\hline Age & 1.02 & $0.99-1.06$ & .1734 \\
Female sex & 1.14 & $0.50-2.63$ & .7558 \\
Marfan's disease & 0.30 & $0.03-2.61$ & .2726 \\
Left ventricular function & 1.52 & $0.63-3.64$ & .3507 \\
Reoperation & 2.07 & $0.45-9.50$ & .3494 \\
Root replacement & 1.29 & $0.50-3.33$ & .5966 \\
Arch replacement & 0.63 & $0.20-1.99$ & .429 \\
Concomitant coronary artery & 3.03 & $1.12-8.19$ & .0292 \\
$\quad$ bypass grafting & & & \\
Malperfusion & 2.65 & $1.21-5.79$ & .0146 \\
$\quad$ Time between symptom onset and & 1.01 & $0.99-1.02$ & .26 \\
$\quad$ surgery as a linear variable & & & \\
Time between symptom onset and & 0.51 & $0.23-1.14$ & .09 \\
$\quad$ surgery as a nonlinear variable & & & \\
\hline$H R$, Hazard ratio; $C I$, confidence interval. & & &
\end{tabular}

these 3 groups is another group of patients who, despite aortic dissection, do not seem to develop malperfusion, and may account for the improved late results reported in some studies. In addition, of course, patients with intramural hematoma do not experience malperfusion and have better outcomes.

In the present study, the patients in the early surgery group had slightly higher mortality, but the difference between the groups was not statistically significant. Moreover, the proportion of patients with malperfusion was also higher in this group, and once malperfusion was accounted for, there was no difference in outcomes between the 2 groups.

In keeping with our findings, malperfusion is reportedly present in almost one-third of patients presenting with acute

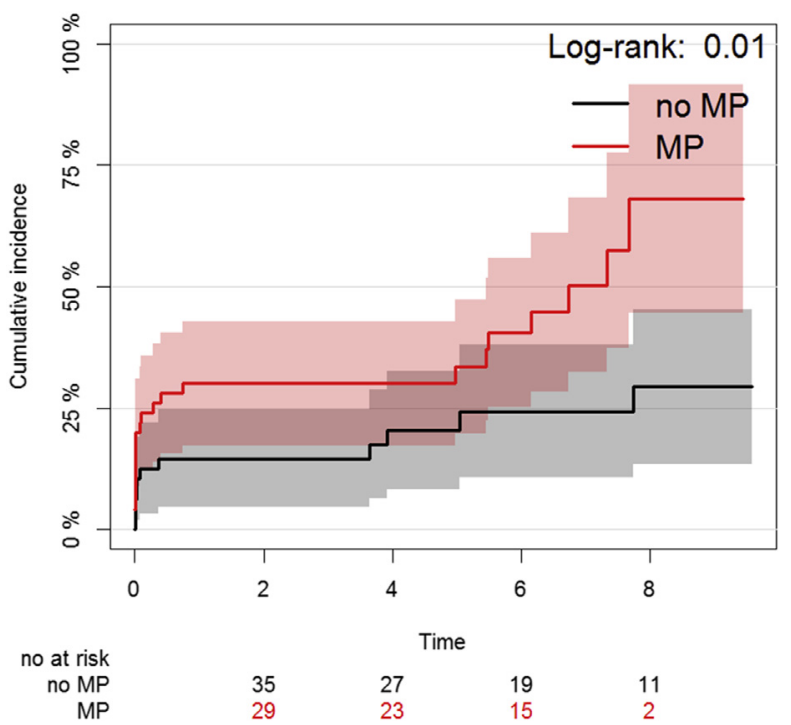

FIGURE 2. Survival comparison of patients with and without malperfusion. $M P$, Malperfusion. 


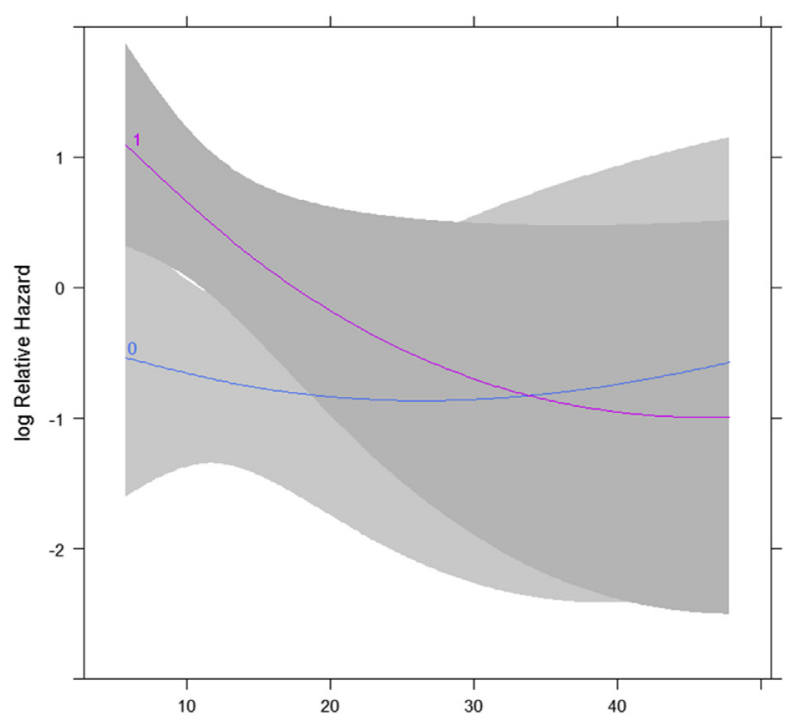

FIGURE 3. Risk-adjusted interaction between malperfusion (1, presence of malperfusion; 0, no malperfusion) and time.

type A aortic dissection. ${ }^{15,16}$ Although subclinical malperfusion does not seem to increase the operative risk, ${ }^{13}$ the presence of clinical malperfusion is associated with poorer outcomes. ${ }^{14}$ Outcomes also vary based on the type of associated malperfusion. Mesenteric ischemia is associated with the worst outcomes and although occurring in only a small percentage of patients, is associated with mortality in up to two-thirds of cases. ${ }^{17,18}$ Cerebral malperfusion is not only associated with increased mortality, but also leads to significant quality of life impairment even if the patient survives. ${ }^{19}$ The incidence of coronary malperfusion due to type A aortic dissection has been reported in up to $15 \%$ cases $^{20}$; however, it can be difficult to evaluate and leads to increased mortality both in the short term and at 5-year follow-up. ${ }^{10,11}$ Hemodynamic instability when associated with malperfusion at presentation has an extremely poor prognosis, and has been shown to be independent of patient age. $^{21}$

Prevention or reversal of malperfusion is the primary goal of operative repair of aortic dissection. ${ }^{16}$ Very early repair may treat the aortic dissection before it has the opportunity to cause organ malperfusion. Even after malperfusion has developed, prompt repair allows for the restoration of perfusion to all compromised organ systems and helps minimize complications. ${ }^{16}$ When malperfusion occurs before operative repair can be carried out, the outcome is often poor. In some cases, delayed operative repair is possible, which often results from diagnostic delay and is usually associated with better outcomes, because these patients self-select themselves to better outcomes given their lack of organ malperfusion. Essentially, the time-related outcome is merely a representation of malperfusion-related outcome. Moreover,

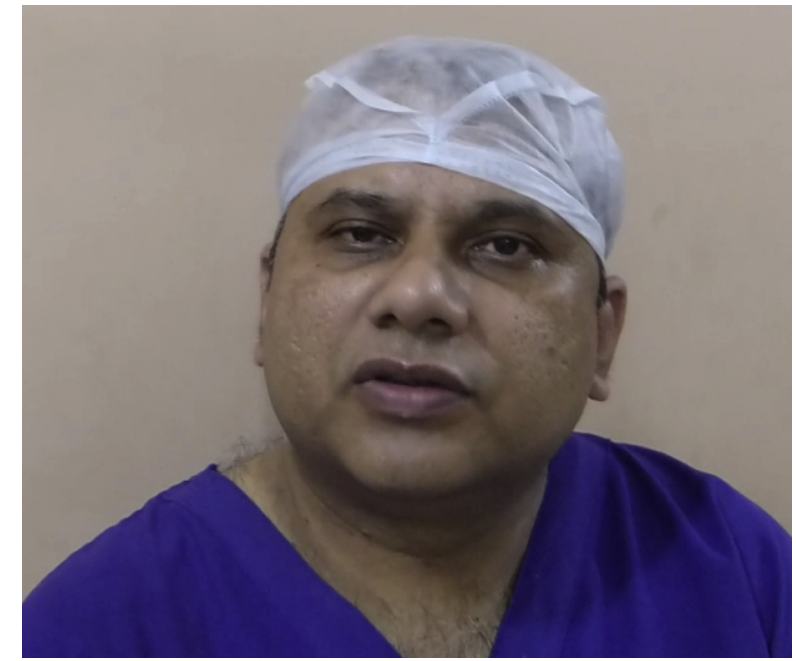

VIDEO 1. Dr Pradeep Narayan discusses the importance of the study findings. Video available at: http://www.jtcvsonline.org/article/S00225223(17)30545-7/addons.

although time-related outcomes can be conflicting, outcomes based on the presence or absence of malperfusion seem to be associated with more consistent findings and a closer association with the pathology.

An important limitation of this study was the inclusion of different types of malperfusions as a single variable. Thus, cardiogenic shock was included together with limb malperfusion. Owing to the very low numbers of more serious malperfusions, such as cardiogenic shock $(\mathrm{n}=2)$, analyzing each type individually was not possible. Moreover, our sample size was relatively small, which may have led to the absence of significant differences between the 2 groups.

In conclusion, malperfusion at presentation rather than the timing of intervention is the major risk factor for death in both the short term and long term in patients undergoing surgical repair of type A aortic dissection. Nonetheless, early operation remains the standard of care for managing type A aortic dissections. This approach prevents the development of malperfusion, and in cases where malperfusion has already developed, offers the best possible option to restore normal perfusion and limit the adverse effects of malperfusion. The important findings of the study are further discussed in Video 1 by Dr Pradeep Narayan.

\section{Conflict of Interest Statement}

Authors have nothing to disclose with regard to commercial support.

\section{References}

1. Eggebrecht H, Naber CK, Bruch C, Kröger K, von Birgelen C, Schmermund A, et al. Value of plasma fibrin D-dimers for detection of acute aortic dissection. J Am Coll Cardiol. 2004;44:804-9. 
2. Erbel R, Alfonso F, Boileau C, Dirsch O, Eber B, Haverich A, et al. Diagnosis and management of aortic dissection. Task Force on Aortic Dissection, European Society of Cardiology. Eur Heart J. 2001;22:1642-81.

3. Scholl FG, Coady MA, Davies R, Rizzo JA, Hammond GL, Kopf GS, et al. Interval or permanent nonoperative management of acute type A aortic dissection. Arch Surg. 1999;134:402-5; discussion 405-6.

4. Golledge J, Eagle KA. Acute aortic dissection. Lancet. 2008;372:55-66.

5. Rogers AM, Hermann LK, Booher AM, Nienaber CA, Williams DM, Kazerooni EA, et al. Sensitivity of the aortic dissection detection risk score, a novel guideline-based tool for identification of acute aortic dissection at initial presentation: results from the International Registry of Acute Aortic Dissection. Circulation. 2011;123:2213-8.

6. Bonser RS, Ranasinghe AM, Loubani M, Evans JD, Thalji NM, Bachet JE, et al Evidence, lack of evidence, controversy, and debate in the provision and performance of the surgery of acute type A aortic dissection. J Am Coll Cardiol. 2011; 58:2455-74

7. Fann JI, Smith JA, Miller DC, Mitchell RS, Moore KA, Grunkemeier G, et al. Surgical management of aortic dissection during a 30-year period. Circulation. 1995;92(9 Suppl):II113-21.

8. Mehta RH, Suzuki T, Hagan PG, Bossone E, Gilon D, Llovet A, et al. Predicting death in patients with acute type A aortic dissection. Circulation. 2002;105: 200-6.

9. Ehrlich MP, Ergin MA, McCullough JN, Lansman SL, Galla JD, Bodian CA, et al. Results of immediate surgical treatment of all acute type A dissections. Circulation. 2000;102(19 Suppl 3):III248-52.

10. Narayan P, Rogers CA, Caputo M, Angelini GD, Bryan AJ. Influence of concomitant coronary artery bypass graft on outcome of surgery of the ascending aorta/ arch. Heart. 2007;93:232-7.

11. Hagan PG, Nienaber CA, Isselbacher EM, Bruckman D, Karavite DJ, Russman PL, et al. The International Registry of Acute Aortic Dissection (IRAD): new insights into an old disease. JAMA. 2000;283:897-903.

12. Tsai TT, Evangelista A, Nienaber CA, Trimarchi S, Sechtem U, Fattori R, et al. Long-term survival in patients presenting with type A acute aortic dissection: insights from the International Registry of Acute Aortic Dissection (IRAD). Circulation. 2006;114(1 Suppl):I350-6.
13. Cho YH, Sung K, Kim WS, Jeong DS, Lee YT, Park PW, et al. Malperfusion syndrome without organ failure is not a risk factor for surgical procedures for type A aortic dissection. Ann Thorac Surg. 2014;98:59-64.

14. Orihashi K. Malperfusion in acute type A aortic dissection: unsolved problem. Ann Thorac Surg. 2013;95:1570-6.

15. Czerny M, Schoenhoff F, Etz C, Englberger L, Khaladj N, Zierer A, et al. The impact of pre-operative malperfusion on outcome in acute type A aortic dissection: results from the GERAADA registry. J Am Coll Cardiol. 2015;65:2628-35.

16. Geirsson A, Szeto WY, Pochettino A, McGarvey ML, Keane MG, Woo YJ, et al. Significance of malperfusion syndromes prior to contemporary surgical repair for acute type A dissection: outcomes and need for additional revascularizations. Eur J Cardiothorac Surg. 2007;32:255-62.

17. Di Eusanio M, Trimarchi S, Patel HJ, Hutchison S, Suzuki T, Peterson MD, et al. Clinical presentation, management, and short-term outcome of patients with type A acute dissection complicated by mesenteric malperfusion: observations from the International Registry of Acute Aortic Dissection. J Thorac Cardiovasc Surg. 2013;145:385-90.e1.

18. Kazui T, Washiyama N, Bashar AH, Terada H, Suzuki T, Ohkura K, et al. Surgical outcome of acute type A aortic dissection: analysis of risk factors. Ann Thorac Surg. 2002;74:75-81; discussion 81-2.

19. Conzelmann LO, Hoffmann I, Blettner M, Kallenbach K, Karck M, Dapunt O, et al. Analysis of risk factors for neurological dysfunction in patients with acute aortic dissection type A: data from the German Registry for Acute Aortic Dissection type A (GERAADA). Eur J Cardiothorac Surg. 2012;42:557-65.

20. Girdauskas E, Kuntze T, Borger MA, Falk V, Mohr FW. Surgical risk of preoperative malperfusion in acute type A aortic dissection. J Thorac Cardiovasc Surg. 2009; 138:1363-9.

21. Zindovic I, Sjögren J, Bjursten H, Danielsson E, Ingemansson R, Nozohoor S. Impact of hemodynamic instability and organ malperfusion in elderly surgical patients treated for acute type A aortic dissection. J Card Surg. 2015;30:822-9.

Key Words: aortic and arterial disease, aortic dissection or intramural hematoma, aortic surgery 